\title{
AN ASSETS-BASED APPROACH TO BEREAVEMENT CARE
}

Dr Bruce Rumbold

College of Science, Health and Engineering

School of Psychology and Public Health

La Trobe University

Bundoora 3086 Victoria

T: +61 394798814

E: b.rumbold@latrobe.edu.au

Professor Samar Aoun (Corresponding author)

School of Nursing, Midwifery \& Paramedicine

Curtin University

GPO Box U1987

Perth, 6845 Western Australia

T: +61 419911940

E: s.aoun@curtin.edu.au 


\begin{abstract}
A survey of bereaved clients of four funeral providers in Australia confirms a public health model predicting that over half the group would demonstrate low risk of complicated grief, another third moderate risk, while a small minority would meet the criteria for prolonged grief disorder. The survey also shows differing patterns of need and sources of support for each of the three groups. While our findings support targeting the bereavement care provided by health services, our primary interest is in the care received by most bereaved people. Some is provided in the community through the everyday activities of healthcare professionals. Most comes from a range of people already involved in the everyday lives of those recently bereaved. We contend that the most effective way to provide bereavement care is to support these 'everyday assets', ensuring that their care is recognized, appreciated, and not disrupted by over-reach from professional services.
\end{abstract}

\title{
Introduction
}

Not everyone who receives bereavement support needs it and not everyone who needs bereavement support receives it. Until this misalignment can be addressed through evidence-informed approaches, palliative care services will struggle to make appropriate decisions about providing, or not providing, bereavement support (Breen et al. 2014). A related question is who best provides bereavement support or, more importantly, who is perceived by bereaved people to have offered them support when they needed it.

\section{The Public Health Model for Bereavement support}

To explore these questions we conducted a population-based survey of bereaved clients of four funeral providers in Australia (Aoun et al. 2015). We examined the fit of the data collected with our proposed conceptual framework 'the Public Health Model for Bereavement Support' (Aoun et al. 2012). We used the PG-13 to estimate the level of risk of complicated grief to have an idea of the severity of the bereavement experience, as described in detail in an earlier article (Aoun et al 2015). To estimate the level of unmet needs, we used a straightforward question whether the bereaved felt they had enough support, and invited them to list in order of importance the sources of this support. Three risk groups were identified: low, moderate and high. The proportions were a close fit with the model. The predicted and actual proportions of low risk were $60 \%$ vs $58.4 \%$ respectively; the moderate risk proportions were $30 \%$ vs $35.2 \%$, and the high risk proportions were $10 \%$ vs $6.4 \%$ respectively (Figure 1) (Aoun et al. 2015).

[Figure 1 about here] 
The spread of demographic characteristics of the bereaved and the deceased, the cause of death, and impact on the health of the bereaved revealed differentiated experiences that align with the expectation of low, moderate and high bereavement risk. A typical bereaved person in the low risk group would be grieving an aged parent whose death was expected. The person's physical and mental health would not be affected by the death. A typical bereaved person in the moderate risk group would be grieving a deceased spouse, both of mature years, through either an expected or unexpected death. The survivor's physical and mental health would be challenged to some extent by the death, but the bereaved person's resilience would be adequate with some additional support. A typical bereaved person in the high risk group would be grieving either a child or a spouse. Both the deceased person and the bereaved spouse would be younger than those associated with the two lower risk groups. Death would be mainly unexpected, affecting the physical and mental health of the bereaved (Aoun et al. 2015).

On the whole, the bereaved in the low risk group reported being satisfied that they received enough support and did not need more. A third of those in the moderate risk group were not satisfied that they received enough support, while nearly two thirds of those in the high risk group perceived that they did not receive enough support (Aoun et al. 2015). Typically the low risk group had the support they needed already in place, from their community social networks. The moderate group needed some additional support from the wider community, including general support from various professionals, while the high risk group needed support from mental health professionals. It could be noted that we are dealing here with self-reported needs, not professional assessments of those needs. Further, we asked about support received, not support sought. Thus it is quite possible that some who reported inadequate levels of support did not take the initiative to ask for help, or confounded their wants with substantial need for support. Our interest however is in eliciting the experiences of community members and making these the first point of response.

\section{Community vs professional help}

These findings come from work in progress by a research team based at Curtin University under the leadership of Professor Samar Aoun. They support the case for containing and targeting the bereavement care programs of palliative care and other health services. However, our primary interest is in the care that supports the majority of bereaved people.

The findings illustrated by Figure 2 suggest that the primary sources of bereavement care for most people are their existing social networks, supplemented for some by networks formed during a period spent caring for a dying family member. Such informal networks consisted of family, friends and funeral providers as the top three sources of support, followed by financial or legal advisor, religious or spiritual advisor and the internet. The networks formed during the caring period included, in 
decreasing order, the general practitioner, nursing home, hospital, pharmacist, community group, palliative care service, and school based advisor. A few people, particularly those in the high risk group, sought support from a bereavement support group or a mental health professional such as a social worker, psychologist or psychiatrist (Aoun et al. 2015).

\section{[Figure 2 about here]}

It can further be inferred that, for people in the low risk category, responsibilities for care have been shared and support comes from networks that have had time to develop - both in their everyday lives and in the caregiving they have negotiated for an ageing parent. In the moderate risk category, bereaved people have often been the primary providers of care for a spouse. During this period they have presumably built up professional care networks similar to those relied upon by people in the first category; but in addition they are likely to be exhausted by their role as caregiver, and their immersion in caregiving over a significant period may have disrupted the friendship and support networks upon which they relied at earlier times in their lives. Those in the third category appear to be people with sparse supportive networks in their everyday lives who in addition have had little or no time to form supportive relationships with other caregivers involved in their relative's dying and death.

These findings support the work of Benkel et al (2009), who further suggest that professional help is required mainly when social networks are dysfunctional or when the bereaved person doesn't want to place an extra burden on these social relationships. That is, professional help, vital though it may be in some instances, complements the so-called 'informal care', not the other way round.

\section{An asset-based approach}

A bereavement care policy informed by this public health perspective should have as its foundation the strengthening and support of the principal resource for bereavement care, community social networks. In these networks resilience is formed and sustained. This is consistent with an asset-based model of public health (Baker 2014; Morgan \& Ziglio 2007; Sigerson \& Gruer 2011), where the focus is upon creating well-being and supporting a sense of coherence in people's lives (Brooks \& Kendall 2013), not focusing principally upon deficits. An asset-based approach is based in community development strategies that strengthen existing community assets and thus enhance that community's capacity to care. It seeks to maximise that community's resources before (or at least alongside) mobilising a professional response. A deficit-based response on the other hand tends to identify needs and develop professional programs to meet them with little consideration of community capacity (Sharpe et al. 2000). The dilemma caused in bereavement care by such a professionalised response has already been discussed (Rumbold and Aoun, 2014; Schut et al., 2001; Currier et al., 2008). Public health bereavement 
policy should support and enhance community caring networks and improve the quality, but not necessarily extend the reach, of professional services. Under the public health model for bereavement support, palliative care services are called upon to invest their efforts principally in developing community capacity for bereavement care rather than seeking to deliver specialized bereavement services to relatives and friends of those who have received palliative care services (Rumbold and Aoun, 2014).

It is also worth clarifying an important distinction between an asset-based approach and the use of volunteers by professional services. An asset-based approach is intended to promote a community's capacity to care and to preserve its autonomy in doing so. Professional services will contribute to this, but in a partnership role where contributions, both training and direct services, are negotiated with the community. In contrast, volunteer programs are overwhelmingly controlled by the professional services that recruit them. While capacity is developed in the volunteers themselves, their activities are constrained to conform to the mission of the professional service. That is, volunteers are recruited to extend professional services (Horey et al. 2015). They do not provide a complementary form of community care, or increase community capacity - although they may well do so if they take the skills they have learned through volunteering and use them in situations beyond health service supervision.

A continuum of support between caregiving and bereavement support needs lends itself well to palliative care services that have the opportunity to assess sources for grief and bereavement support in the lead up to the patient's expected death (Sealey et al, 2015). This relationship between caregiving and bereavement experience has recently been raised as an important area for further research (Stroebe \& Boerner, 2015). We endorse these suggestions, with the further proviso that such research needs to include explicit and careful attention to informal support. Most respondents to our survey are clearest about support provided by professionals, but were less specific about informal support. While $90 \%$ of respondents listed family and friends as providers of support, we lack detail about the ways in which this support was provided. This is almost inevitable in a survey where it is easier to be specific in listing professional care providers than the myriad of small contributions that come from friends, family and neighbours. Certainly researchers who studied informal networks of care for people dying in the community found they had to persist to identify the contribution made by informal caregivers (Horsfall et al., 2011). Frequently, members of the support network downplayed their contribution until network members began to explore what the caregiving experience might have been without it (Horsfall et al., 2012). The same researchers have demonstrated the complementary contributions of formal and informal caregivers in providing effective end of life care that distributes responsibility between all those involved in care (Abel et al., 2013; Horsfall et al., 2013). The aftermath of such caregiving has not yet been 
investigated through a bereavement lens, but their findings of increased social capacity among the network points toward resilience in the experience of loss.

\section{Concluding remarks}

Care is provided in the community by a range of people, only some of whom are healthcare practitioners (and these healthcare practitioners contribute to care through their everyday activities, not through bereavement programs). Most care comes from a range of people already involved in the everyday lives of those recently bereaved. These people are assets already in place, contributing to each other's resilience. The most effective way to provide bereavement care is to support these 'everyday assets', ensuring that their care is recognized, appreciated, and not disrupted by over-reach from professional services.

A next step to be taken on the basis of a survey like ours is asset-mapping within surveyed communities (Baker 2014; Crawford 2005; Sharpe et al. 2000), and investigating ways in which community capacity for bereavement care is developed. Evidence here is mixed. Clearly in some cases prior losses have developed people's capacity to care creatively for friends and family whose loss is immediate. In other cases, little seems to have been learned, and an encounter with others' immediate loss is more likely to reawaken unresolved grief than to mobilise a capacity to care. Understanding how and why these differing responses emerge is fundamental to developing community assets from the universal experience of loss.

\section{REFERENCES}

Abel, J, Walter, T, Carey, L, Rosenberg, J, Noonan, K, Horsfall, D, Leonard, R, Rumbold, B \& Morris, D 2013, 'Circles of Care: should community development redefine the practice of palliative care?', BMJ Supportive \& Palliative Care, vol. 3, no. 4, pp. 383-388. Available from: <http://dx.doi.org/10.1136/bmjspcare-2012-000359>

Aoun, SM, Breen, L, Howting, D, Rumbold, B, McNamara, B, \& Hegney, D 2015, 'Who needs bereavement support? A population based survey of bereavement risk and support need', PLoS One, vol.10, no.3, e0121101. Available from: $<$ http://dx.doi.org/10.1371/journal.pone.0121101>

Aoun, S, Breen, LJ, O'Connor, M, Nordstrom, C \& Rumbold, B 2012, 'A public health approach to bereavement support services in palliative care', Australian and New Zealand Journal of Public Health, vol. 36, no. 1, pp.14-16.Available from: <http://dx.doi.org/10.1111/j.1753-6405.2012.00825.x> 
Baker, D 2014, 'Developing and implementing a robust asset-based approach to public health', Perspectives in Public Health, vol. 134, no. 3, pp. 129-130. Available from: <http://dx.doi.org/10.1177/1757913914530842>

Benkel, I, Wijk, H, \& Molander, U 2009, 'Family and friends provide most social support for the bereaved', Palliative Medicine, vol. 23, no.4, pp.141-149. Available from: <http://dx.doi.org/10.1177/0269216308098798>

Breen, L, Aoun, SM, O'Connor, M, \& Rumbold, B 2014, 'Bridging the Gap between Research, Policy, and Practice in Bereavement Support in Palliative Care: An International Perspective', Death Studies, vol. 38, no. 1-5, pp.54-61. Available from: $<$ http://dx.doi.org/10.1080/07481187.2012.72545>

Brooks, F, Kendall, S 2013, 'Making sense of assets: what can an assets-based approach offer public health?' Critical Public Health, vol. 23, no. 2, pp.127-130.

Crawford, F 2005, Doing it differently: an asset-based approach to well-being. Edinburgh, Scottish Council Foundation \& NHS Scotland. Available from: http://www.healthscotland.com/documents/1035.aspx

Currier JM, Neimeyer RA and Berman JS. 2008. The effectiveness of psychotherapeutic interventions for bereaved persons: A comprehensive quantitative review. Psychological Bulletin.134: 648-61.

Horey, D, Street, AF, O'Connor, M, Peters, L, \& Lee, SF 2015, 'Training and supportive programs for palliative care volunteers in community settings', Cochrane Database of Systematic Reviews, Issue 7 . Art. No.: CD009500. Available from: <http://dx.doi.org/10.1002/14651858.CD009500.pub2>

Horsfall, D, Noonan, K , \& Leonard, R 2011, Bringing Our Dying Home: Creating Community at End of Life. Research Report, University of Western Sydney. Available from: <www.cancercouncil.com.au $>$

Horsfall, D, Noonan, K, \& Leonard, RJ 2012, 'Bringing our dying home: how caring for someone at end of life builds social capital and develops compassionate communities', Health Sociology Review, vol. 21, no.4, pp.373-382. Available from: $<$ http://dx.doi.org/10.5172/hesr.2012.21.4.373>

Horsfall, D, Leonard, R, Noonan, K, \& Rosenberg, J 2013, 'Working together - apart: exploring the relationships between formal and informal care networks for people dying at home', Progress in Palliative Care, vol. 21, no. 6, pp.331-336. Available from: <http://dx.doi.org/10:1179/1743291X12Y.0000000047> 
Morgan, A, Ziglio, E 2007, 'Revitalising the evidence base for public health: an assets model', Promotion and Education, suppl. 2, pp. 17-22.

Rumbold B and Aoun SM 2014. Bereavement and Palliative Care: A Public Health Perspective. Progress in Palliative Care 22(3), 131-135.

Schut $\mathrm{H}$, Stroebe M, van den Bout J, Terheggen M. 2001. The efficacy of bereavement interventions: determining who benefits. In: Stroebe M, Hansson R, Stroebe W, Schut $\mathrm{H}$, editors. Handbook of bereavement research: Consequences, coping, and care. Washington, DC: American Psychological Association; 2001. p. 705-727.

Sealey M, Breen L, O'Connor M, Aoun SM 2015. A scoping review of bereavement risk assessment instruments: Implications for palliative care. Palliative Medicine. DOI: 10.1177/0269216315576262 pmj.sagepub.com.

Sharpe, P, Greaney, M, Lee, P \& Royce, S 2000, 'Assets-oriented community assessment', Public Health Reports, vol. 115, pp.205-211.

Sigerson, D \& Gruer, L 2011, Asset-based approaches to health improvement. Glasgow, NHS Scotland.

Stroebe, M \& Boerner, K 2015, 'Caregiving and bereavement research: bridges over the gap', Palliative Medicine, vol. 29, no. 7, pp.574-576. Available from: http://dx.doi.org/10.1177/0269216315585952 
TWO figures in a separate attachment.

Figure 1: The Public Health Model: Predicted (in brackets) and Actual Proportions for the three risk groups

Source: Aoun, SM, Breen, L, Howting, D, Rumbold, B, McNamara, B \& Hegney, D 2015, 'Who needs bereavement support? A population based survey of bereavement risk and support need', PLoS One, vol.10, no. 3, e0121101.

Figure 2: Sources of bereavement support accessed grouped according to types of support

Source: Aoun, SM, Breen, L, Howting, D, Rumbold, B, McNamara, B \& Hegney, D 2015, 'Who needs bereavement support? A population based survey of bereavement risk and support need', PLoS One, vol.10, no. 3, e0121101. 


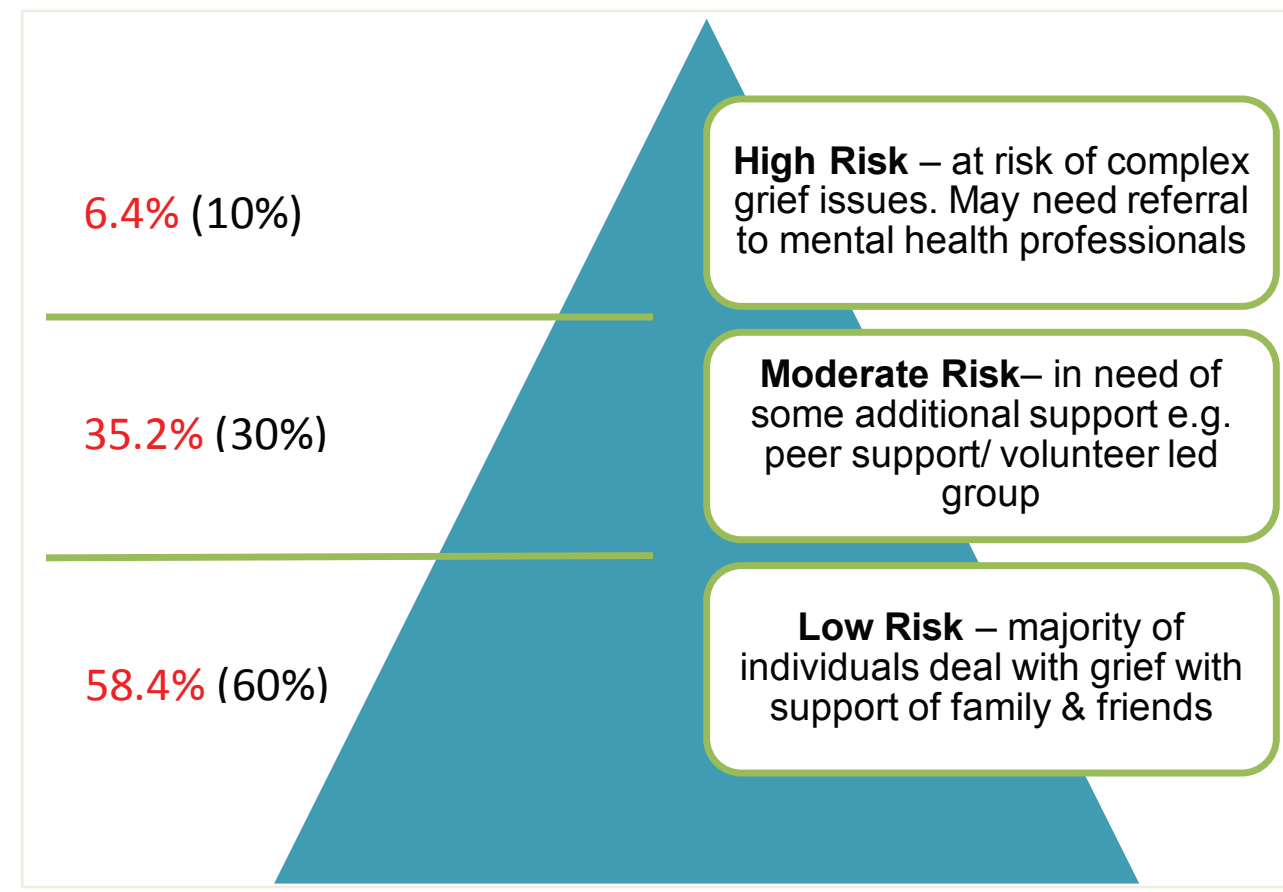




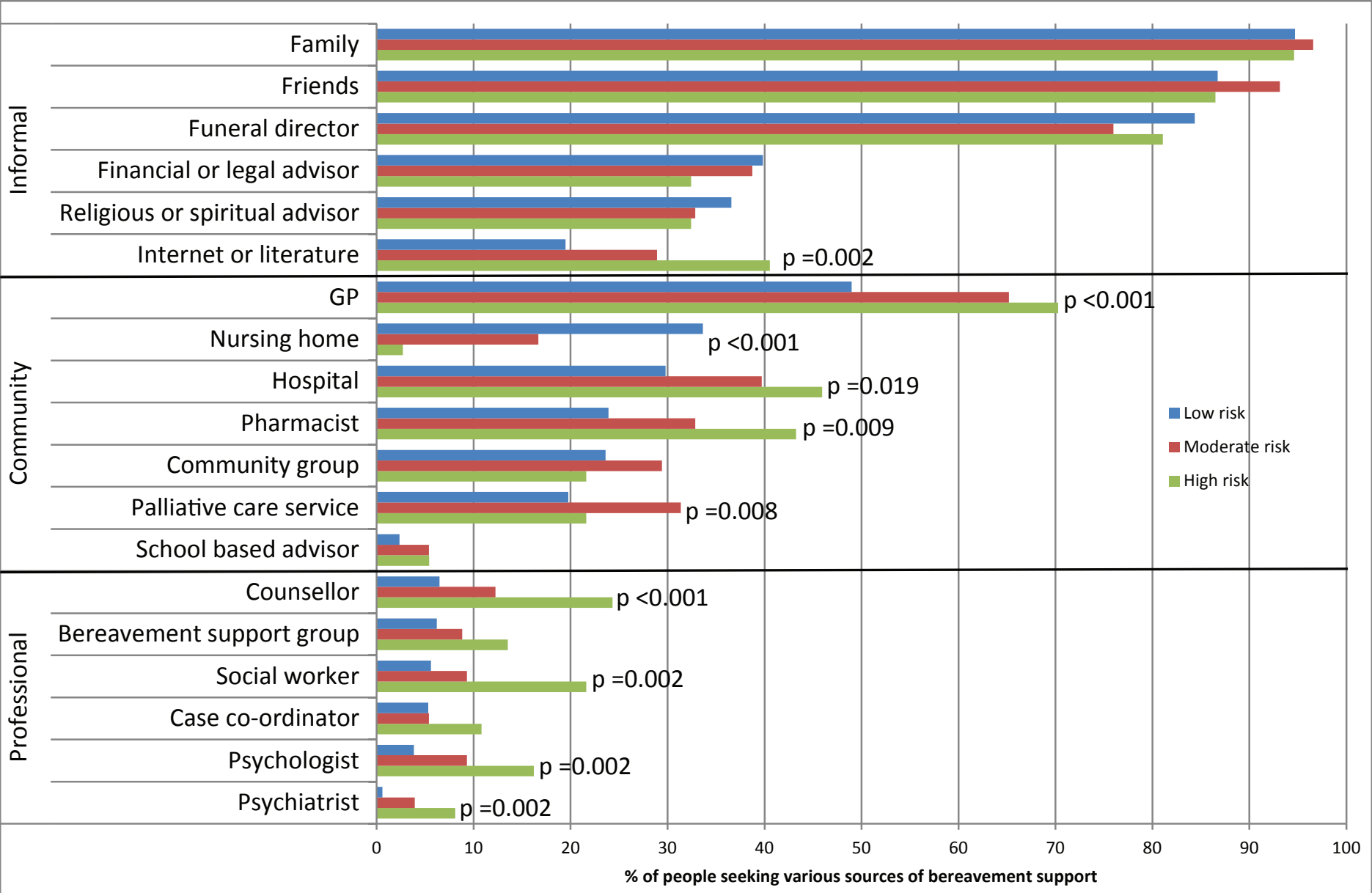




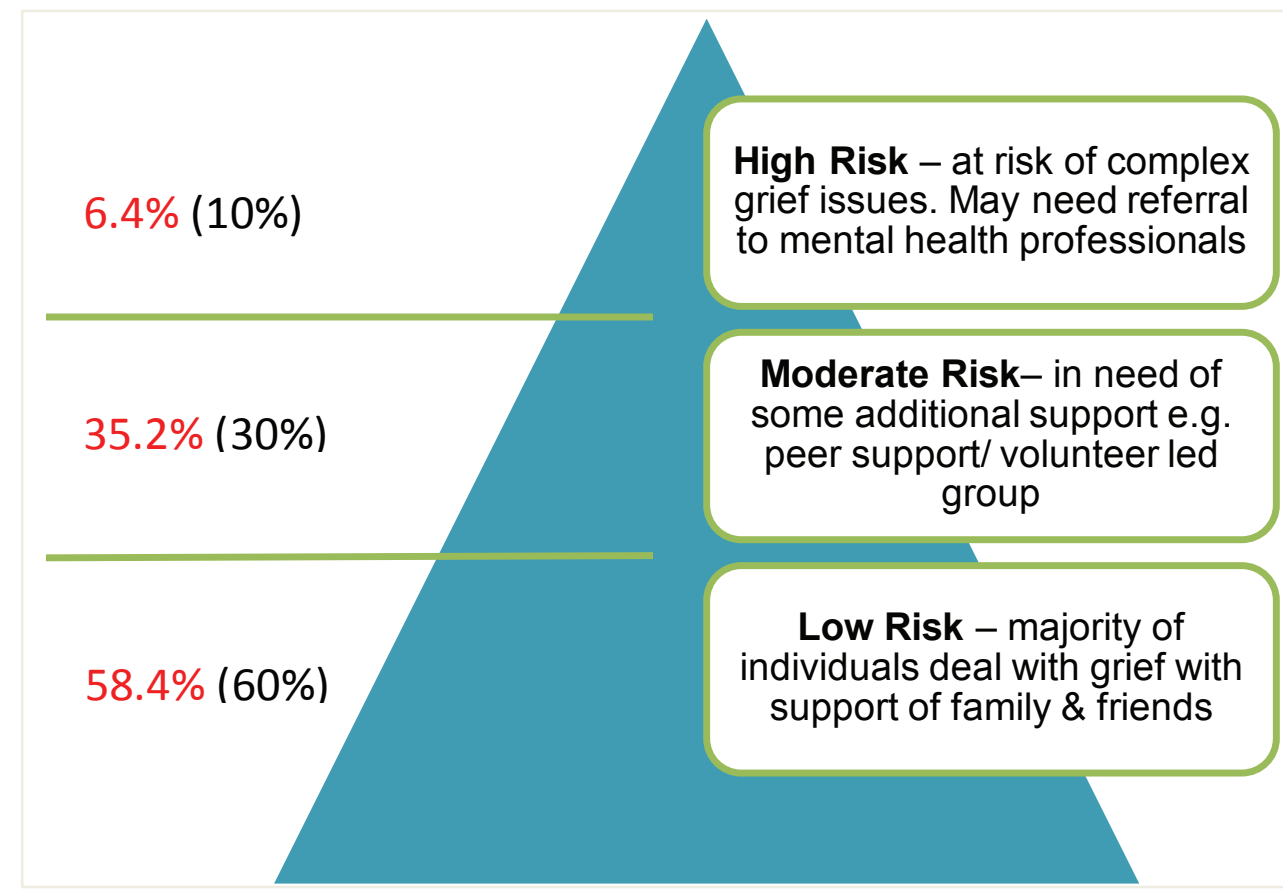




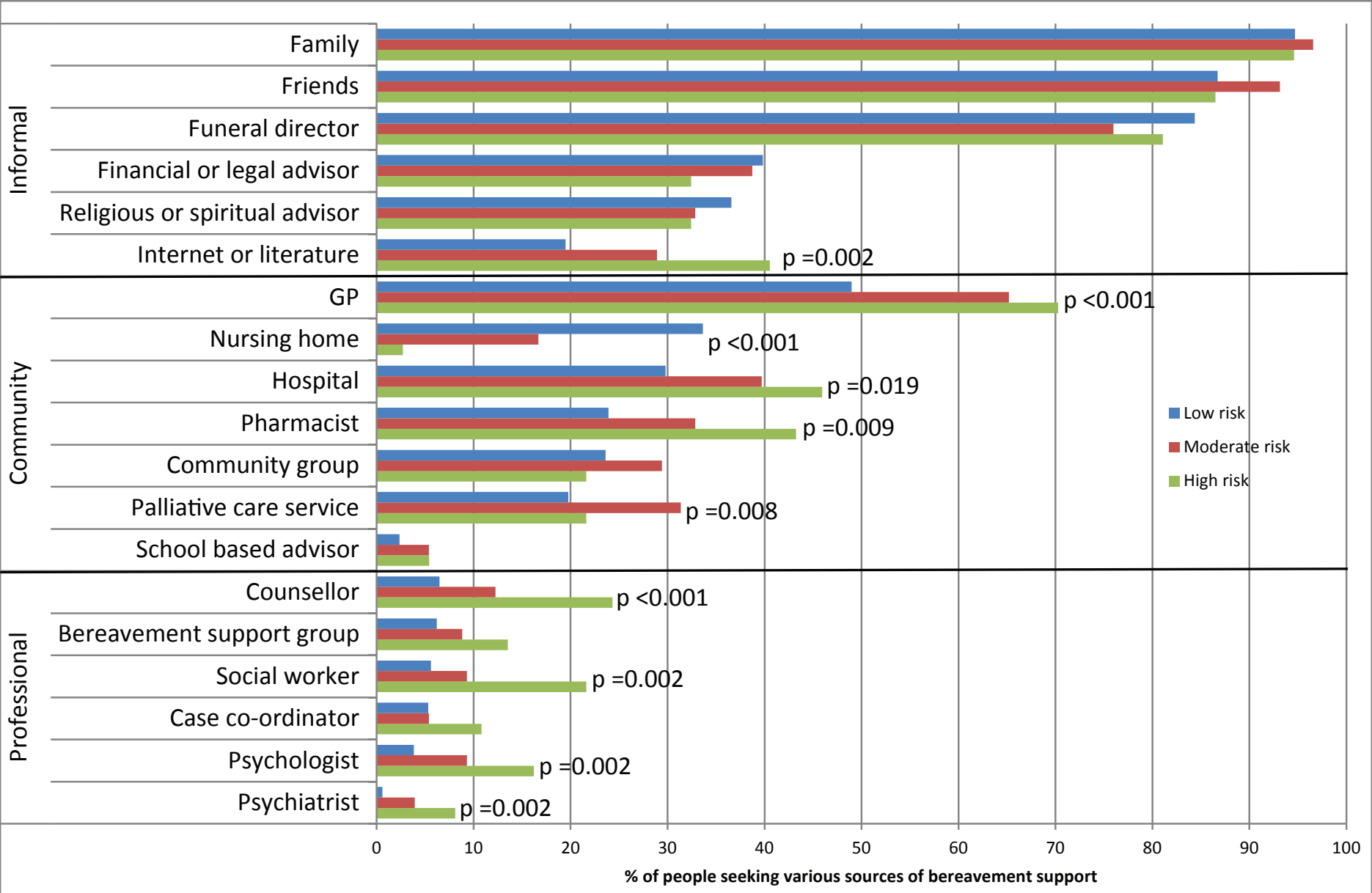

